\title{
ATIVIDADE ANTIBACTERIANA DE EXTRATOS DE Senna alata L. Roxb. SOBRE A MANCHA BACTERIANA DO MARACUJAZEIRO
}

Clenilda Tolentino Bento da Silva ${ }^{1}$, Alessandra Keiko Nakasone Ishida ${ }^{2}$, Walkymário Paulo Lemos ${ }^{3}$, Alessandra de Nazaré Reis Freire ${ }^{4}$

${ }^{1}$ Pedagoga, Mestre em Agricultura Familiar e Desenvolvimento Sustentável pela Universidade Federal do Pará. Núcleo de Ciências Agrárias e Desenvolvimento Rural. Técnica da Embrapa Amazônia Oriental, Belém, PA - Brasil

${ }^{2}$ Engenheira Agrônoma, Doutora em Fitopatologia pela Universidade Federal de Lavras. Lavras, MG. Pesquisadora da Embrapa Amazônia Oriental, Belém, PA Brasil

${ }^{3}$ Engenheiro Agrônomo, Doutor em Entomologia pela Universidade Federal de Viçosa. Viçosa, MG. Pesquisador da Embrapa Amazônia Oriental, Belém, PA Brasil

${ }^{4}$ Graduanda em Agronomia pela Universidade Federal Rural da Amazônia, Belém, PA - Brasil

Autor para correspondência: alessandra.ishida@embrapa.br. Embrapa Amazônia Oriental. Belém, PA - Brasil

Recebido em: 08/04/2017 - Aprovado em: 10/06/2017 - Publicado em: 20/06/2017 DOI: 10.18677/EnciBio 2017A17

A mancha bacteriana, causada por Xanthomonas axonopodis pv. passiflorae, é uma das principais doenças do maracujazeiro no Estado do Pará, sendo sua elevada incidência favorecida pelas condições climáticas locais. Extratos de plantas medicinais têm sido utilizados com resultados promissores no controle de fitopatógenos e, por esse motivo, essa pesquisa avaliou a atividade antibacteriana de extratos alcoólicos de Senna alata sobre o crescimento in vitro de $X$. axonopodis pv. passiflorae e na redução da bacteriose em casa de vegetação. Os extratos foram obtidos de folhas e vagens de $S$. alata. In vitro, os extratos foram incorporados ao meio 523 a $1 \%$, e em seguida depositadas alíquotas de $100 \mu \mathrm{L}$ da suspensão bacteriana e espalhadas nas placas com alça de Drigalski. As placas foram incubadas por $48 \mathrm{~h}$, a $28^{\circ} \mathrm{C}$, com delineamento experimental inteiramente casualizado. Foram realizadas contagens das Unidades Formadoras de Colônia (UFC) nas placas. In vivo, foram aplicados extratos, a $1 \%$, em plantas de maracujazeiro três dias antes da inoculação do patógeno. Em ambos os ensaios utilizou-se oxicloreto de cobre como tratamento controle. Extrato de folhas de $S$. alata inibiu $14,94 \%$ do crescimento bacteriano em maracujazeiro, enquanto oxicloreto de cobre inibiu $100 \%$. Nossos estudos revelaram que extrato de vagens de S. alata e oxicloreto de cobre reduzem, significativamente, a severidade da doença em plantas de maracujazeiro em 37,82\% e 44,0\%,respectivamente.

PALAVRAS-CHAVE: controle alternativo, Passiflora edulis, Xanthomonas axonopodis pv. passiflorae. 


\title{
ANTIBACTERIAL ACTIVITY OF Senna alata L. Roxb. EXTRACTS AGAINST BACTERIAL STAIN OF PASSION FRUIT TREES
}

\begin{abstract}
The bacterial spot, caused by Xanthomonas axonopodis pv. passiflorae, is one of the major diseases of passion fruit trees in the State of Pará, and its high incidence is favored by local climatic conditions. Extracts of medicinal plants have been used with promising results in the control of phytopathogens and, for this reason, this research evaluated the antibacterial activity of alcoholic extracts of Senna alata on the in vitro growth of $X$. axonopodis pv. passiflorae, and in the reduction of bacteriosis in green house conditions. The extracts were obtained from leaves and pods of $S$. alata. In the studies In vitro, the extracts were incorporated into 523 medium, with concentration of $1 \%$, and then $100 \mu \mathrm{L}$ aliquots of the bacterial suspension were plated and spread in Drigalski loop plates. The plates were incubated during $48 \mathrm{~h}$, at $28^{\circ} \mathrm{C}$, with a completely randomized experimental design. The Colony Forming Units (CFU) were counts on the plates. In vivo, extracts with concentration of $1 \%$ were applied in passion fruit plants three days before to pathogen inoculation. In both trials, copper oxychloride was the control treatment. Senna alata leaves extract inhibited $14.94 \%$ of bacterial growth in passion fruit plants, while copper oxychloride inhibited $100 \%$. Our studies revealed that $S$. alata pods extract and copper oxychloride reduced significantly the severity of the disease in passion fruit plants in $37.82 \%$ and $44.0 \%$, respectively.
\end{abstract}

KEYWORDS: alternative control, Passiflora edulis, Xanthomonas axonopodis pv. passiflorae.

\section{INTRODUÇÃO}

A mancha bacteriana, conhecida também por bacteriose ou morte precoce do maracujazeiro (Passiflora edulis f. flavicarpa), é causada por Xanthomonas axonopodis pv. passiflorae. Surtos severos dessa doença comprometem seriamente a cultura, causando elevados prejuízos aos agricultores por inviabilizar seus cultivos (SÃO JOSÉ et al., 2011). Nesse contexto, os extratos vegetais com potencial antimicrobiano poderão contribuir como uma das estratégias de controle de fitopatógenos, haja vista que o uso indiscriminado de antibióticos pode favorecer o aparecimento de populações resistentes de bactérias, contribuindo para a ineficiência de controle dos produtos atualmente no mercado (ISHIDA \& HALFELDVIEIRA, 2009; MELO et al., 2016).

O uso de extratos de plantas medicinais é conhecido há séculos no tratamento de patologias humanas (ASSIS JUNIOR et al., 2013), devido principalmente a ação antimicrobiana conferida por metabólitos secundários, presentes em diferentes extratos de plantas medicinais (PACHECO et al., 2015). Posteriormente, o seu emprego se estendeu, também, para o controle de doenças de plantas por apresentarem potencial contra fitopatógenos, tornando-se uma alternativa promissora para reduzir o uso de agrotóxicos na agricultura (SANTOS et al., 2013).

Senna alata L. Roxb. também conhecida como alcapulco, fedegosão, mangerioba-do-pará, mata-pasto-grande, mangerioba-grande e fedegoso-gigante é uma espécie daninha pertencente à família Leguminosae, subfamília Caesalpinioideae, e apresenta propriedades medicinais, que lhe conferem indicação para tratar diversas doenças, dentre elas, anemia, congestão do fígado, febre tifóide, herpes, infecção e infestação da pele por bactérias e fungos (PLANTAMED, 2016). 
Essa espécie é frequentemente encontrada nas pastagens em processo de degradação da região amazônica, sendo que, os estudos fitoquímicos evidenciaram em suas folhas, diferentes classes químicas, destacando-se, ácidos graxos, alcalóides e compostos fenólicos, como antraquinonas, cumarinas, flavonóides, saponinas e taninos (RODRIGUES et al., 2009). O alcaloide indólico dimérico presente nas folhas de $S$. alata possui uma excelente atividade analgésica e antiinflamatória (MACEDO et al., 2016). Por essas características, desponta entre as espécies com grande potencial antimicrobiano. Trabalhos têm demonstrado o potencial antifúngico do extrato alcoólico de $S$. alata em importantes fungos fitopatogênicos como Myrothecium roridum, agente casual do cancro-de-mirotécio em meloeiro (MEDEIROS et al., 2011), Fusarium oxysporum, agente causal da fusariose do meloeiro (MEDEIROS et al., 2012), Aspergillus niger (OGUNJOBI \& ABIALA, 2013), Monosparacus cannonballus agente causal do colapso do meloeiro (VIANA et al., 2008), Curvularia sp. e Xanthomonas campestris pv. citri (TAVENOOTH, 2016).

Quando comparados aos produtos sintéticos, os extratos vegetais oferecem vantagens porque geram compostos secundários menos tóxicos, que degradam com maior facilidade no ambiente e atuam de forma ampla além de serem derivados de recursos renováveis (SANTOS et al., 2013). Assim, esta pesquisa avaliou o efeito de extratos alcoólicos de folhas e vagens de $S$. alata sobre o crescimento in vitro de $X$. axonopodis pv. passiflorae e na redução da severidade da mancha bacteriana do maracujazeiro em casa de vegetação.

\section{MATERIAL E MÉTODOS \\ Origem, isolamento e preservação do patógeno}

Os ensaios foram conduzidos no Laboratório de Fitopatologia e casa de vegetação da Embrapa Amazônia Oriental, Belém, Pará. $O$ isolado de $X$. axonopodis pv. passiflorae foi obtido de folhas de maracujazeiro com lesões características da mancha bacteriana, provenientes do município de Igarapé-Açu, PA. O isolado encontra-se preservado em água destilada esterilizada, no Laboratório de Fitopatologia da Embrapa Amazônia Oriental.

\section{Obtenção dos extratos}

Para a obtenção dos extratos vegetais, folhas e vagens de $S$. alata provenientes de Tomé Açu, PA, foram transportadas para o Laboratório de Fitopatologia da Embrapa Amazônia Oriental. Realizou-se a assepsia do material pela lavagem em água corrente, imersão em álcool $(70 \%)$ por um minuto, e solução de Hipoclorito de sódio $(\mathrm{NaClO})$ na concentração de $1 \%$, por dois minutos. Em seguida, procederam-se três enxagues com água destilada estéril para eliminação do cloro residual. Folhas e vagens foram dispostas sobre papel toalha para absorção do excesso de água. O material foi seco em estufa com circulação de ar forçado, a $40^{\circ} \mathrm{C}$, até peso constante e triturado em moinho elétrico para obtenção do pó (adaptado de PEDRAL et al., 2015).

Foram utilizados $0,8 \mathrm{~g}$ do pó de cada material (folhas e vagens), para $8 \mathrm{~mL}$ de álcool etílico comercial, $92,8^{\circ} \mathrm{GL}$, mantidos sob agitação em "shaker", a $200 \mathrm{rpm}$ por 20 minutos. Em seguida, o material homogeneizado foi transferido para geladeira por 24h. Passado esse período, os extratos foram centrifugados a $7.000 \mathrm{rpm}$, por 10 minutos a $4^{\circ} \mathrm{C}$, e filtrados em membranas do tipo Millipore, com porosidade de $0,22 \mu \mathrm{m}$, que foram usados logo após sua obtenção (adaptado de AMORIM et al., 2011). 


\section{Ensaio in vitro}

Para avaliação da atividade antibacteriana in vitro, os extratos alcoólicos de S. alata foram incorporados ao meio 523 (KADO \& HESKETT, 1970) fundente a $55^{\circ} \mathrm{C}$ e $1 \%$. Como tratamento controle utilizou-se oxicloreto de cobre, na dosagem de 2,5g/L. Após a solidificação do meio de cultura nas placas contendo os tratamentos, foram depositadas alíquotas de $100 \mu \mathrm{L}$ da suspensão bacteriana na concentração de $0,3 \mathrm{UA} / \mathrm{mL}$, diluída em solução salina $\mathrm{NaCl} 0,85 \%$ até $10^{-6} \mathrm{UFC} / \mathrm{mL}$ e espalhada nas placas com o auxílio de uma alça de Drigalski.

Como testemunha foi utilizado o meio de cultura sem os extratos. As placas foram incubadas por $48 \mathrm{~h}$ a $28^{\circ} \mathrm{C}$. O delineamento experimental foi o inteiramente casualizado, com 4 tratamentos e 5 repetições. A avaliação foi realizada através da contagem das Unidades Formadoras de Colônia (UFC) nas placas. Os dados obtidos foram submetidos à análise de variância e a comparação das médias realizada pelo teste de Scott \& Knott, a 5\% de probabilidade, utilizando-se programa estatístico SISVAR.

\section{Ensaio in vivo}

Sementes de maracujá, cultivar Redondo amarelo (cultivar suscetível), foram semeadas em vasos com capacidade para $3 \mathrm{~kg}$. Após as plantas apresentarem de duas a quatro folhas verdadeiras, um desbaste foi realizado deixando apenas uma planta por vaso. O tratamento controle com oxicloreto de cobre foi utilizado na dosagem de $2,5 \mathrm{~g} / \mathrm{L}$ e os extratos vegetais, a $1 \%$, diluídos com água de torneira obtidos como descrito anteriormente.

Todos os tratamentos foram aplicados manualmente na face inferior das folhas até o ponto de escorrimento, três dias antes da inoculação do patógeno. A suspensão bacteriana foi obtida seguindo o mesmo protocolo do ensaio in vitro. A testemunha foi pulverizada com água de torneira. Após a inoculação, as plantas foram mantidas em câmara úmida por 24 horas.

O delineamento experimental foi em blocos casualizados com cinco repetições (uma planta/repetição). A severidade da mancha bacteriana foi avaliada aos 2, 4, 6, 8, 10 e 12 dias após a inoculação do patógeno. Os valores obtidos serviram de base para o cálculo da área abaixo da curva de progresso da doença (AACPD), de acordo com SHANER \& FINNEY (1977). Os dados foram submetidos à análise de variância e a comparação das médias realizada pelo teste de Scott \& Knott, a 5\% de probabilidade, utilizando-seo programa estatístico SISVAR.

\section{RESULTADOS E DISCUSSÕES}

No ensaio in vitro, o oxicloreto de cobre, utilizado como tratamento controle, inibiu $100 \%$ do crescimento bacteriano, diferindo dos demais tratamentos. O extrato alcoólico de folhas de S. alata inibiu $14,94 \%$ do crescimento bacteriano, diferindo da testemunha, enquanto o extrato alcoólico da vagem de $S$. alata apresentou resultado similar à testemunha (Tabela 1).

Os resultados dessa pesquisa corroboram com os trabalhos de MEDEIROS et al. (2011), que registraram que todos os extratos de partes vegetais de S. alata foram eficientes em inibir o crescimento micelial de Myrothecium roridum, agente casual do cancro-de-mirotécio em meloeiro. $O$ extrato alcoólico da vagem promoveu maior inibição do crescimento de $M$. roridum, seguido do extrato de raiz e caule. Similarmente, OGUNJOBI \& ABIALA (2013) evidenciaram a eficiência do extrato aquoso de $S$. alata contra Aspergillus niger. Extratos alcoólicos de diferentes partes 
de $S$. alata também foram testados no controle do crescimento micelial de Fusarium oxysporum em meloeiro (MEDEIROS et al., 2012), os autores confirmaram que todas as partes testadas foram eficazes no controle da fusariose sendo que, os extratos de raiz e vagens foram os mais eficientes para inibir o crescimento micelial do patógeno, além do extrato de caule que, também, mostrou-se eficiente.

TABELA 1. Efeito de oxicloreto de cobre, extratos alcoólicos de folhas e vagens de Senna alata, in vitro, sobre o crescimento de Xanthomonas axonopodis pv. passiflorae.

\begin{tabular}{lcc}
\hline \multicolumn{1}{c}{ Tratamentos } & UFC $^{\mathrm{a}}$ & $\begin{array}{c}\text { \% de controle em relação à } \\
\text { testemunha }\end{array}$ \\
\hline Oxicloreto de cobre & $0,00 \mathrm{c}^{\mathrm{b}}$ & 100 \\
Extrato de folhas de S.alata & $84,20^{\mathrm{b}}$ & 14,94 \\
Extrato de vagens de S.alata & $94,60^{\mathrm{a}}$ & 4,44 \\
Testemunha & $99,00^{\mathrm{a}}$ & - \\
\hline aUFC = Unidade Formadora de Colônia. ${ }^{\mathrm{b}}$ Médias seguidas de mesma letra na coluna \\
não diferem entre si pelo teste de Scott \&Knott 5\% de probabilidade. CV = 8,30\%.
\end{tabular}

Pesquisas têm concluído que diferentes extratos vegetais e óleos essenciais inibem o crescimento de bactérias fitopatogênicas. AMORIM et al. (2011) detectaram atividade antimicrobiana no extrato de gengibre \{Zingiber officinale (Willd.) Roscoe\} e de óleos de citronela \{Cymbopogon nardus (L.) Rendle\} e cravo (Caryophyllus aromaticus L.), que foram capazes de inibir o crescimento de Ralstonia solanacearum em todas as concentrações testadas, com destaque para o óleo de cravo, seguido pelo extrato de gengibre.

Para Xanthomonas campestris pv. campestris, patógeno responsável pela podridão negra das crucíferas, DIDWANIA et al. (2013) avaliaram a atividade antibacteriana de extratos de plantas de cebola de cabeça (Allium cepa L.), nim (Azadirachta indica A. Juss) e cravo de defunto (Tagetes erecta L.), que mostraram boa atividade antibacteriana na concentração de $50 \%$.

O efeito bactericida de óleos essenciais de orégano (Origanum vulgare L.) e tomilho (Thymus vulgaris L.) sobre Xanthomonas albilineans, causadora da doença escaldadura das folhas em cultivares de cana-de-açúcar, foi avaliado por RAMOS et al. (2012), que verificaram considerável atividade antibacteriana desses sobre o patógeno,que foram utilizados com uma concentração mínima inibitória (CMI) de $7,81 \mu \mathrm{L} / \mathrm{mL}$.

No ensaio in vivo desta pesquisa, verificou-se que o oxicloreto de cobre e o extrato de vagem de $S$. alata reduziram a severidade da mancha bacteriana do maracujazeiro em $44,0 \%$ e $37,82 \%$,respectivamente, diferindo da testemunha e não diferindo entre si (Tabela 2).

Trabalhos têm demonstrado a eficiência do oxicloreto de cobre no controle de bacterioses de plantas. ISHIDA \& HALFELD-VIEIRA (2009) relataram que o oxicloreto de cobre proporciona bom controle da bacteriose do maracujazeiro. JUNQUEIRA et al. (2011) observaram que os produtos, Cuprozeb® (oxicloreto de cobre + mancozeb), acibenzolar-S-metil - ASM, Agro-mos $®$, Fosfito de potássio, fosetyl-AI, Gesso agrícola e CPAC-GE reduziram a severidade da bacteriose em campo. 
TABELA 2. Efeito de oxicloreto de cobre, extratos alcoólicos de folhas e vagens de Senna alata no controle da mancha bacteriana (Xanthomonas axonopodis pv. passiflorae).

\begin{tabular}{lcc}
\hline \multicolumn{1}{c}{ Tratamentos } & AACPD & $\begin{array}{c}\text { \% de controle em relação à } \\
\text { testemunha }\end{array}$ \\
\hline Oxicloreto de cobre & $121,82 b^{\mathrm{b}}$ & 44,00 \\
Extrato de vagens de S.alata & $135,28^{\mathrm{b}}$ & 37,82 \\
Extrato de folhas de S.alata & $207,53^{\mathrm{a}}$ & 4,60 \\
Testemunha & $217,55^{\mathrm{a}}$ & - \\
\hline
\end{tabular}

${ }^{a} \mathrm{AACPD}=$ área abaixo da curva do progresso da doença. ${ }^{\mathrm{b}}$ Médias seguidas de mesma letra não diferem entre si pelo teste Scott $\&$ Knott $5 \%$ de probabilidade. $\mathrm{CV}=$ $36,82 \%$.

No presente trabalho, observou-se que o extrato de vagens de $S$. alata reduziu a severidade da doença e não diferiu do tratamento controle, o que indica que o extrato estudado pode ser uma alternativa viável ao uso do oxicloreto de cobre no controle mancha bacteriana do maracujazeiro. Outros extratos vegetais como os extratos aquosos de nim (Azadirachta indica), eucalipto citriodora \{Corymbia citriodora (Hook.) K.D. Hill \& L.A.S. Johnson\} apresentaram potencial de redução da bacteriose em maracujazeiro (BULHÕES et al., 2012), demonstrando que os princípios ativos presentes nos extratos de plantas medicinais podem além de inibir o desenvolvimento de fitopatógenos, reduzir a severidade de doenças bacterianas. SIMEON \& ABUBAKAR (2014) estudaram os extratos de nim (Azadirachta indica), folhas de eucalipto (Eucalyptus citrodorus L.), grama de limão (Cymbopogon citratus Stapf), bulbo de alho (Allium sativum Linn.), gengibre (Zingiber officinale), babosa \{Aloe vera (L.) Burm. f.\} e o sal de bórax no manejo da podridão mole em batata, verificando que os extratos de grama de limão, alho, babosa, nim e o sal de bórax promoveram efeito inibitório sobre Pectobacterium spp.

Assim como os extratos, os óleos essenciais de plantas medicinais também apresentam efeito antimicrobiano. SILVA et al. (2012) verificaram que os óleos essenciais de eucalipto (Corymbia citriodora) e laranjeira \{Citrus sinensis (L.) Osbecke\} reduziram significativamente a severidade da podridão mole em alface em casa de vegetação e não diferiram do Mycoshield $\AA$, fungicida utilizado como tratamento controle.

Existem na literatura inúmeras pesquisas demonstrando a eficiência, in vitro, de extratos vegetais sobre diversos fitopatógenos, no entanto, são poucos os relatos do efeito desses extratos aplicados diretamente em plantas para avaliar a redução da infestação desses fitopatógenos (AMORIM et al., 2011). No presente trabalho, o extrato alcoólico das vagens de $S$. alata apresentou um bom desempenho no ensaio in vivo, reforçando o potencial desse extrato para ser inserido como mais uma ferramenta de controle e manejo integrado da doença em cultivos amazônicos. Além disso, o uso desse extrato no controle da bacteriose caracteriza-se como um método alternativo podendo minimizar os impactos ambientais, preservar a saúde humana e contribuir de forma significativa para uma produção agrícola sustentável.

\section{CONCLUSÃO}

O extrato alcoólico de folhas de $S$. alata promove inibição do crescimento bacteriano in vitro, enquanto, o extrato alcoólico de vagens reduz a severidade da mancha bacteriana do maracujazeiro em casa de vegetação. 


\section{REFERÊNCIAS}

AMORIM, E. P. R.; ANDRADE, F. W. R.; MORAES, E. M. S.; SILVA, J. C.; LIMA, R. S.; LEMOS, E. E. P. Atividade antibacteriana de óleos essenciais e extratos vegetais sobre o desenvolvimento de Ralstonia solanacearum em mudas de bananeira. Revista Brasileira de Fruticultura. Volume Especial, p. 392-398, 2011. Disponível em: <http://dx.doi.org/10. 1590/S0100-29452011000500050>.

ASSIS JUNIOR, L. R.; GARCEZ, F. R.; GARCEZ, W, S.; GUTERRES, Z. R. Pregnanos e outros constituintes das raízes de Macrosiphonia petraea (A. St.-Hill.) Kuntze (Apocynaceae). Química Nova, v. 36, n. 4, p. 519-523, 2013. Disponível em:<http://dx.doi.org/10. 1590/S0100-40422013000400006.

BULHÕES, C. C.; BONALDO, S. M.; SANTOS, B.T.; TRENTO, R. A. Produtos alternativos no controle de antracnose (Colletotrichum gloeosporioides), cladosporiose (Cladosporium herbarum) e bacteriose (Xanthomonas campestris pv. passiflorae) em maracujazeiro no Norte de Mato Grosso. Revista Ciências Exatas e da Terra e Ciências Agrárias, v. 7, n. 1, p. 12-19, 2012. Disponível em: http://revista.grupointegrado.br/revista/index.php/campodigital.

DIDWANIA, N; SADANA, D.; TRIVEDI, P. C. Antibacterial activity of a few medicinal plants against Xanthomonas campestris pv. campestris. International Journal of Research in Pharmaceutical Sciences, v. 4, n. 2, p. 177-182, 2013. Disponível em: https://www.pharmascope.org/index.php/ijrps/index, Acesso em: 27 de setembro de 2016.

ISHIDA, A. K. N.; HALFELD-VIEIRA, B. A. Mancha-bacteriana do maracujazeiro (Xanthomonas axonopodis pv. passiflorae): etiologia e estratégias de controle. Belém, PA: Embrapa Amazônia Oriental, 2009. 22p (Documentos, 357).

JUNQUEIRA, K. P.; FALEIRO, F. G.; UESUGI, C. H.; JUNQUEIRA, N. T. V.; BELLON, G.; SANTOS, E. C.; RAMOS, L. N. Desempenho agronômico de maracujazeiros tratados com produtos alternativos e fertilizantes foliares. Revista Brasileira de Fruticultura [online], v. 33, n. 1, p. 040-047, 2011. Disponível em: < http://dx.doi.org/10.1590/ 0100-29452011005000019.

KADO, C. I; HESKETT, M. G. Selective media for isolation of Agrobacterium, Corynebacterium, Erwinia, Pseudomonas and Xanthomonas. Phytopathology, Saint Paul, v. 60, n. 6, p. 969-976, 1970.

MACEDO, E. M. S.; ALAN E SILVA, J. G.; SILVA, M. G. V. Quimiodiversidade e Propriedades Biofarmacológicas de Espécies de Senna Nativas do Nordeste do Brasil. Revista Virtual de Química, v. 8, n. 1, p. 169-195, 2016. Disponível em: <http://rvq.sbq.org.br. doi:10.5935/1984-6835.20160012>.

MEDEIROS, E. V.; VIANA, M. G.; ALBUQUERQUE, C. C.; VIANA, F. A.; SILVA, K. M. B. Extrato etanólico de Senna alata no controle de Myrothecium roridum, agente causal do cancro-de-mirotécio. Planta Daninha, v. 29, n. 3, p. 577-583, 2011. Disponível em: <http://dx.doi.org/10. 1590/S0100-83582011000300011>. 
MEDEIROS, E. V.; VIANA, M. G.; ALBUQUERQUE, C. C.; VIANA, F. A.; SILVA, K. M. B. Extrato etanólico de Senna alata no controle de Fusarium oxysporum, causador da murcha-de-fusarium do meloeiro. Revista Brasileira Engenharia Agrícola Ambiental, v. 16, n. 11, p. 1166-1170, 2012. Disponível em: <http://dx.doi.org/10.1590/S1415-43662012001100004>.

MELO, P. A. F. R.; ALVES, E. U.; MARTINS, C. C.; ANJOS NETO, A. P; PINTO, K. S. M.; ARAÚJO, L. R.; VIEIRA, C. P.; NASCIMENTO, L. C. Extratos de Caesalpinia ferrea e Trichoderma spp. no controle da tramissibilidade de Colletotrichum sp. em sementes de Sideroxylon obtusifolium (Sapotaceae). Revista Brasileira de Plantas Medicinais, v. 18, n. 2, p. 494-501, 2016. Disponível em <http://dx.doi.org/10.1590/1983-084X/15_191>.

OGUNJOBI, A. A.; ABIALA, M. A. Antimicrobial activity of Senna alata and Phyllanthus amarus. Global Journal of Pharmacology, v. 7, n. 2, p. 198-202, 2013. Disponível em: <http://www.idosi.org/gjp/7(2)13/16. pdf. doi: 10.5829/idosi.gjp.2013.7.2.74179>.

PACHECO, D. R.; SOARES, D. E. D.; SILVA NETO, C. M.; SILVA, G. A.; PRADO, R. S. AVALIAÇÃO DA ATIVIDADE ANTIFÚNGICA DE Curcuma longa SOBRE Candida parapsilosis. Revista de Patologia Tropical, v. 44, n. 3, p. 258-270, 2015. Disponível em: <http://dx.doi.org/10.5216/rpt.v44i3.38022>.

PEDRAL, A. L.; BARBOSA, J. S.; SANTOS, G. R.; XAVIER, A. C. R. ARIMATÉA, C. C.; FONTES, A. S.; SILVA, G. F.; BARRETTO, L. C. O. Caracterização físicoquímica de folhas da Moringa oleifera desidratadas por secagem convectiva e liofilização. Revista Brasileira de Produtos Agroindustriais, v.17, n.1, p. 33-39, 2015. Disponível em: http://www.deag.ufcg.edu.br/rbpa/rev171/Art1715.pdf.

PLANTAMED. Disponível em:

http://www.plantamed.com.br/plantaservas/especies/Senna alata.htm2016. Acesso em: 24 de agosto de 2016.

RAMOS, E. T. A.; BORGES, K. C. A. S.; TEBALDI, V. M. R. Atividade bactericida dos extratos hidroalcoólicos de hera-roxa e capim-limão e dos óleos essenciais de orégano, tomilho e melaleuca sobre Xanthomonas albilineans. Cadernos Unifoa Edição n.19, 2012.

RODRIGUES, I. M. C.; SOUZA FILHO, A. P. S.; FERREIRA, F. A. Estudo fitoquímico de Senna alata por duas metodologias. Planta Daninha, v. 27, n. 3, p. 507-513, 2009. Disponível em: <http://dx.doi.org/10. 1590/S0100-83582009000300011>.

SANTOS, P. L.; PRANDO, M. B.; MORANDO, R.; PEREIRA, G. V. N.; KRONKA, A. Z. Utilização de extratos vegetais em proteção de plantas. Enciclopédia Biosfera, v. $9, \quad$ n. $17, \quad$ p. 2562-2576, 2013. Disponível em: $<$ http://hdl.handle.net/11449/137597>. 
SÃO JOSÉ, A. R.; PIRES, M. de M. Aspectos gerais da cultura do maracujá no Brasil. In: PIRES, M. de M.; SÃO JOSÉ, A. R.; CONCEIÇÃO, A. O. (Eds.). Maracujá: avanços tecnológicos e sustentabilidade. Ilhéus, Editus, 2011, 237p.

SHANER, G.; FINNEY, R. The effect of nitrogen fertilization on the expression of slow-mildewing resistance in Knox Wheat. Phytopathology, v. 67, n. 8, p. 10511056, 1977.

SILVA, C. L.; SOUZA, E. B.; FELIX, K. C. S.; SANTOS, A. M. G.; SILVA, M. V.; MARIANO, R. L. R. Óleos essenciais e extratos vegetais no controle da podridão mole em alface crespa. Horticultura Brasileira, v. 30, n. 4, 2012. Disponível em: http://dx.doi.org/10.1590/S0102-05362012000400012.

SIMEON, A. U.; ABUBAKAR, A. Evaluation of some plant extracts for the control of bacterial soft rot of tubers. American Journal of Experimental Agriculture, v. 4, n.12, p.1869-1876, 2014. Disponível em: doi: 10.9734/AJEA/2014/12309. <http://www.journalrepository.org/media/journals/AJEA_2/2014/Aug/Simeon4122014 AJEA12309_1.pdf>.

TAVENOOTH, V. Effect of the bioextract to control the Curvularia leaf spot and canker of lemon. International Journal of Geomate, v. 11, n. 28, p. 2862-2865, 2016. Disponível em: http://www.geomatejournal.com/sites/default/files/articles/28622865-1288-Vithaya-Dec-2016-R3.pdf.

VIANA, M. G.; ALBUQUERQUE, C. C.; MEDEIROS, E. V.; VIANA, F. A.; SILVA, K. M. B. Avaliação do potencial fungicida de extratos etanólicos de Senna alata contra Monosparacus cannonballus. Ciência e Agrotecnologia, v. 32, n. 5, p.1387-1393, 2008. Disponível em: <http://dx.doi.org/10. 1590/S1413-70542008000500005. 